\title{
Género degenerado. Redefinición sociocultural de las identidades de género y sexuales en Sirena Selena vestida de pena de Mayra Santos-Febres y Nadie me verá Ilorar de Cristina Rivera Garza
}

\author{
Silvia M. Gianni ${ }^{1}$
}

\section{Resumen}

El análisis de Sirena Selena vestida de pena y Nadie me verá llorar se propone mostrar cómo las construcciones de las identidades de género y sexuales encuentran en el espacio estético nuevas configuraciones personales, colectivas, nacionales, de clase y origen étnico. A través del estudio del lenguaje y de la historia narrada por medio del uso de los cuerpos, se rastrean y complejizan los espacios de transgresión de límites y certezas para que en estos se logren evidenciar las diversificaciones que favorecen un nuevo planteamiento de los lugares de la identidad de género y sexual. Los cuerpos disidentes de los/as protagonistas (prostitutas, locas, travestis) -castigados y encerrados en el manicomio mexicano o abiertos a todo tipo de transgresión en el Caribe- contribuyen a explorar un terreno donde la transitividad y ambigüedad son los rasgos definitorios de las nuevas identidades, dando lugar a una escritura "des-identitaria" y "de-generada", también por lo que concierne el género literario.

\section{Palabras clave}

Ambigüedad; transgresión; marginalidad; performatividad; diversidades

\section{Abstract}

The analysis of Sirena Selena vestida de pena and Nadie me verá llorar aims to show how the construction of gender and sexual identities create, within the aesthetic space, new configurations in terms of personal, collective, national, class, and ethnic identities. Through the study of language and history narrated by the use of bodies, the spaces for transgression of limits and certainties develop and tangle to finally express the diversities that allow a new approach to the spaces of gender and sexual identity. The dissident bodies of the protagonist/s (prostitutes, mad women,

1 Italiana. Doctora en Ciencias Lingüísticas, Filológicas y Literarias por la Universidad Católica de Milán, Italia. Profesora de Lengua Española de la Universidad Católica de Milán, en la Facultad de Ciencias Lingüísticas y Literaturas Extranjeras. Correo electrónico: gianni.silvia@gmail.com 
transvestites) -tortured and imprisoned in the Mexican madhouses, open to all type of transgression in the Caribbean- contribute to explore a zone where transitivity and ambiguity are the defining features of the new identities, giving place to "dis-identity" and "de-gendered" writing, also for what concerns the literary genre.

\section{Keywords}

Ambiguity; transgression; marginality; performance; diversity

\section{Resumo}

A análise de Sirena Selena vestida de pena e Nadie me verá llorar propõe mostrar como as construções das identidades de gênero e sexual encontram no espaço estético novas configurações pessoais, coletivas, nacionais, de classe e de origem étnica. Através do estudo da linguagem e da história contada mediante o uso dos corpos, se rastreiam e se complexam os espaços de transgressão de limites e certezas para que se possam expressar as diversificações que favorecem uma nova reflexão e abordagem dos lugares da identidade de gênero e sexual. Os corpos dissidentes dos/das protagonistas (prostitutas, loucas, travestis) -castigados e mantidos no manicômio mexicano, abertos a todo tipo de transgressão no Caribe- contribuem para a exploração de um terreno onde a transatividade e a ambiguidade são os traços de definição das novas identidades, dando lugar a uma escritura "des-identitária" e "de-generada", também respeito ao gênero literário.

\section{Palavras-chave}

Ambigüidade; transgressão; marginalidade; performatividade; diversidade

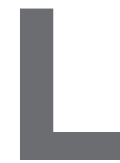

a identidad es, por excelencia, un territorio fronterizo. Por esta razón el acercamiento a este tema ha implicado siempre un cruce entre diversas disciplinas: la antropología, la sociología, los estudios culturales, el psicoanálisis.

Toda identidad, social o subjetiva, racial o nacional, está atravesada por la marca de género y de sexo, y en esa distinción entre masculino y femenino se encierran todas las paradojas de las identidades: la ilusión de centralidad, de certeza, de integralidad, de estabilidad y de coherencia interna como imagen de autopercepción personal o social.

Exactamente al revés de lo que se aparenta, en las novelas que vamos a analizar la representación de las diversidades sexuales, que se configuran en los sujetos discursivos, permite apreciar la transitividad y el carácter móvil de las identidades e indica una toma de conciencia hacia el cambio de los patrones culturales establecidos. 
El enfoque de Sirena Selena vestida de pena (2000) de la puertorriqueña Mayra Santos-Febres y Nadie me verá llorar (1999) de la mexicana Cristina Rivera Garza nos ayuda a indagar sobre cómo, ya desde hace más de una década, se representan, se construyen y se destruyen las diferentes nociones de la identidad de género y sexual (masculina, femenina, heterosexual y homosexual) a través de los discursos del narrador y de los personajes.

Se trata de dos textos que, a partir de miradas totalmente distintas y con técnicas distantes entre sí, desautorizan y desarticulan las nociones fijas y binarias sobre las que asienta el concepto de identidad, ya que hacen de la transgresión y de la ambigüedad los parámetros fundamentales con los cuales acercarse a nuevos espacios donde lo identitario -nacional y cultural- se cruza con lo sexual y corporal.

Las dos escrituras, altamente diferenciadas, albergan propuestas narrativas que van desde la ficcionalización de la historia nacional y médica de México, durante la etapa de la modernización de la época del porfiriato, a la representación del escenario transcaribeño, metaforizado por los cuerpos híbridos de un travesti-bolerista y de otros sujetos que manifiestan su ambigüedad sexual, es decir, cuerpos permeables que subrayan una estructura abierta a mutaciones y un espacio donde se hace posible todo tipo de violaciones de las normas fijas.

En ambos casos los cuerpos disidentes de las prostitutas, las locas, los travestis, las drags ${ }^{2}$ y las lesbianas, que se desplazan a lo largo de las novelas, constituyen los espacios de transgresión que permiten el traspaso de los límites establecidos y la violación de las certezas, dando así lugar a una escritura que "des-identariza" y "degenera" los núcleos internos organizadores de las identidades. Además, en su cuestionamiento, las dos producciones discursivas ponen en relieve los diversos aspectos que componen la identidad de género, es decir evidencian que a la mera expresión subjetiva hay que sumar su presentación ante lo demás3: la elección sexual -ya sea homo, hetero o bisexual-, los roles de género, y otras distinciones que cooperan a descodificar esta complejidad, ayudándonos a comprenderla. Asimismo, enfatizan el hecho que aunque el sexo y el género están relacionados, no

2 Se denomina drag al tipo de travestismo en el que un individuo de determinado género utiliza ropa socialmente asignada al género opuesto. Con este término se describe a un hombre o una mujer que se viste y actúa como lo que se conoce como esterotipos de una mujer de rasgos exagerados, con una intención primordialmente histriónica que se burla de las nociones tradicionales de la identidad de género y los roles de género (Merriam-Webster's Dictionary). Es una forma de personificación femenina y transformismo en el que una persona altera su apariencia y los patrones de su personalidad para ajustarlos al comportamiento y apariencia de una mujer de caricatura. El origen etimológico es ampliamente debatido. Existe una teoría según la cual el término surge en la época del burlesque victoriano donde el verbo "to drag", "arrastrar", hacía referencia a las faldas y vestidos largos portados por algunos actores masculinos en los espectáculos de burlesque (World Wide Words 1996-2004).

3 La identidad de género del travesti, por ejemplo, puede presentarse como una expresión de género mujer. 
son la misma cosa, pues constituyen dos áreas distintas de la práctica social (Rubin, 1989, 54).

Al desestabilizar las categorías tradicionales en las que radica la idea de identidad y al vaciar su función de instrumento de regímenes regularizadores, tanto si actúan como categorías normalizadoras de estructuras opresivas, como "si sirven de puntos de encuentro de una oposición liberadora de esa misma opresión" (Butler, 2000, 85), se pone en marcha un proceso de desencialización del género y del sexo que empuja hacia nuevas interpretaciones de las representaciones de género y de la sexualidad en el espacio estético 4 . Se rompe, así, la rigidez de las definiciones que condenan en un solo término -género- procesos, niveles y realidades que deben ser diferenciados, configurando un espacio donde las diferencias pueden convertirse en normas sociales (Garber, 1992, 133).

En Sirena Selena vestida de pena y Nadie me verá Ilorar los/las protagonistas son sujetos móviles que ocupan posiciones múltiples, distribuidas a lo largo de varios ejes de diferencia, y atravesados por discursos y prácticas que pueden ser recíprocamente contradictorios, ya que estamos en presencia de sujetos que tienen la capacidad de moverse y dislocarse de manera autodeterminada, de tomar consciencia política y responsabilidad social, incluso en su contradicción y no-coherencia. Se trata entonces de personajes que ocupan los espacios enclavados en las fisuras y grietas de los aparatos de poder-saber (De Lauretis, 2000, 62).

De ahí que emerjan la multiplicidad, movilidad, transitividad y ambigüedad como rasgos peculiares de las identidades. Los sujetos que aparecen en las dos obras demuestran su imposibilidad de categorización y su mutabilidad en cuanto al sexo, puesto que el género es "un hacer", es decir no existe un sujeto preexistente a la acción, sino que en su performatividad se construye y

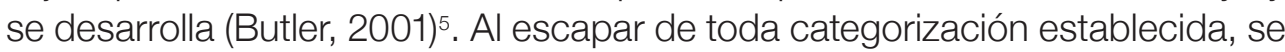
relativizan y transgreden las normas; "desnudando", de esta forma, los mismos mecanismos de representación que funcionan como categorizadores opresivos en la sociedad. El nuevo cuadro conceptual que se compone, por tanto, requiere también técnicas capaces de representar, en el artificio estético, su complejidad.

La sexualidad adquiere una dimensión semiótica en su intersección con la lengua. Por esto Santos-Febres y Rivera Garza recurren a técnicas narrativas que se caracterizan por el desplazamiento de la voz narrativa entre distintas

4 En este sentido, en las dos narraciones se destaca también la influencia de las teorías queer con las que se manifiesta un rechazo de la clasificación de los individuos en categorías universales, como "homosexual", "heterosexual", "hombre", "mujer", ya que estas esconden una enorme posibilidad de variaciones culturales. cuanto doing gender, es decir no existe ningún ser detrás del hacer, del actuar del devenir. 
personas gramaticales -yo, tú, él/ella-y entre distintos sujetos discursivos -personajes, narradores, autores implícitos-. Además, alimentan la experimentación lingüística, entre otros recursos, de numerosas figuras retóricas como la metáfora, la elipsis, la hipérbole y la parodia; a la que se suman varios cambios de perspectiva que producen una ruptura de la linealidad espacio-temporal y la falta de una estructura argumentativa aparentemente coherente; aspecto, este último, aún más evidente en Nadie me verá llorar.

De esta manera, las autoras logran cuestionar, invertir y travestir el sentido unívoco de la identidad y del sexo, proponiendo nuevos espacios de representación y reconfiguración de las realidades nacionales e individuales de sus protagonistas.

\section{Sirena Selena vestida de pena}

La novela de Mayra Santos-Febres hace de la movilidad de los márgenes su característica principal; la oscilación de espacios y territorios, y de las identidades y de los géneros a través de los distintos personajes que pueblan la narración. En otras palabras, el nomadismo que caracteriza Sirena Selena vestida de pena se articula sobre la base de una estrecha relación entre la movilidad física y multitud de identidades y definiciones de raza, sexo, orientación sexual y nacionalidad, hasta tal punto que no se puede reducir a una sola definición.

Desde el enfoque espacial, el relato se desplaza, con un doble movimento, entre Puerto Rico y la República Dominicana, pero también hay numerosas referencias a la realidad haitiana, lo que amplía la representación de un escenario transcaribeño al que se añade, como destino final anhelado, la ciudad de Nueva York, pues es en la metrópoli norteamericana donde algunos personajes piensan realizar sus sueños. Al mismo tiempo, estos desplazamientos permiten relevar los prejuicios existentes en cada realidad nacional, al tener una imagen del otro que se plasma sobre los esterotipos inculcados.

De manera que, para los puertorriqueños, por ejemplo, la República Dominicana es el lugar de donde salen olas de migrantes en busca de una mejor vida en Puerto Rico. Para el imaginario nacional "boricua", no hay ricos, no hay clases, solo desgraciados que atraviesan el mar arriesgando su vida: "no sabía que había millonarios en República Dominicana. En las noticias sólo se hablaba de dominicanos fugados en yolas, carcomidos por la sal" (SantosFebres, 2000, 109). De igual manera, para los dominicanos, la vecina Haití no es más que un territorio cuyos habitantes "viven como perros realengos y no son como otros extranjeros, elegantes" (Santos-Febres, 2000, 200). Para ellos, el haitiano es el marginal. Se compone así un cuadro que enfatiza los límites políticos, mentales y culturales construidos por lugares comunes y estándares que excluyen y limitan al otro según la escala dominante de valores. 
Los varios movimientos entre los distintos territorios, reales o ideales, van a la par de los movimientos identitarios de género y sexuales, dando lugar a un nomadismo que desarticula la taxonomía binaria de las categorías tradicionales y hace de la ambigüedad un espacio legítimo de supervivencia y placer. En otras palabras, en la constante transgresión de las normas que se infringen en el relato, se crea un espacio donde conviven diferencias y similitudes entre los distintos sujetos marginados, y se eliminan las barreras tras la cuales se enrejaban drags, transexuales, travestis, gays y lesbianas.

El Caribe, de esta manera, se convierte en un cuerpo híbrido, representado por el travesti-bolerista -el protagonista principal-, así como por los otros personajes ambiguos que componen la narración; todos son cuerpos permeables que cooperan a la representación de una estructura abierta a mutaciones y de un espacio donde se hace posible todo tipo de infracciones. En efecto, es la transgresión, bajo sus diferentes manifestaciones, la que permite que el individuo transite de una situación a otra y que plasme su "yo" fuera de sus límites corporales y mentales para adquirir mayor fortaleza y capacidad de adaptarse más fácilmente a la situación y a los cambios necesarios.

Santos-Febres otorga un fuerte poder metafórico al travestismo, instrumento con el que logra representar la situación política, social y cultural de Puerto Rico y del Caribe. El travesti simboliza el estatus político de la isla en cuanto Estado Libre Asociado (E.L.A.), un híbrido que reúne en sí ambigüedades, conflictos y apariencias, una máscara que oculta la verdadera esencia para poder lograr sobrevivir.

Sin embargo, la originalidad de la novela reside, entre otros aspectos, en una escritura que supera la obsesión de la búsqueda de la identidad nacional fuera del yugo colonial a través de la ficción, según los cánones en voga en la narrativa puertorriqueña, especialmente a partir de la década $1970{ }^{6}$, y que propone, en cambio un acercamiento a la realidad a partir de las ambigüedades que el colonialismo inscribe en el cuerpo del colonizado.

El protagonista de Sirena Selena vestida de pena encarna las transformaciones económicas y subjetivas de las identidades caribeñas en la economía global. Es un sujeto "transcaribeño", cuyas fronteras se articulan por medio de la actuación de un joven travesti, en el cual, la utilización del cuerpo se entremezcla con los problemas de su marginalidad. Una marginalidad que espera superar gracias a la explotación de su voz que estremece a todos los que lo oyen cantar. Convirtiéndose en un cantante de bolero que luce un cuerpo femenino codiciado por los demás, Sirena Selena desmorona el andamiaje de las convenciones sociales de género, sexo y nación, y otorga centralidad al concepto de movilidad de lo marginal. La errancia, el nomadismo pasan a ser, entonces, los rasgos básicos de su identidad. 
La representación de la movilidad se da a través del recurso de la metáfora como instrumento que posibilita la configuración de la tensión entre lo que existe y lo que hay que definir, entre la submisión a la trama y la elevación de la invención, entre los significados legitimados y los emergentes, entre sujetos históricos que tienen acceso al discurso y los que, en cambio, quedan excluidos. En este sentido, la metáfora en su papel de "llevar más allá", de "transportar", no se limita a ejercer su función retórica, sino que se desempeña como modalidad y proceso del pensamiento, como una actividad cognitiva y expresiva capaz de alcanzar y producir un determinado nivel de conocimiento que, diferentemente, no sería fácil conseguir (Ricoeur, 1986, 325-327).

La metáfora de la figura del travesti no es nueva en la narrativa latinoamericana, ya que en ella confluyen cruces y conceptualizaciones que bien favorecen la representación de las distintas realidades continentales. A este propósito, Nelly Richards subraya que la hiperalegorización de la identidad como máscara que realiza el travesti pintado "desenmascara la vocación latinoamericana del retoque. Retoque de la falta de lo propio (por el déficit de originalidad que marca las culturas secundarias como culturas de la reproducción) mediante la sobremarca cosmética de lo 'ajeno'” (Richards, 1993, 68). Una expresión que, si se enfoca a partir de una mirada metropolitana, hace de la imitación una valorización ulterior del original. Pero si la mirada es desde y hacia sí mismos, esa copia es también "una sátira postcolonial de cómo el fetichismo primermundista proyecta en la imagen latinoamericana representaciones falsas de originariedad y autenticidad que Latinoamérica vuelve a falsificar en una caricatura de sí misma como Otro para complacer la demanda del otro" (Richards, 1993, 68-69).

Este juego entre la mirada y el deseo ajeno y propio caracteriza la fábula. En el deseo de complacer a quienes la codician, Sirena, así como su "madrina" y empresaria Martha Divine, se adornan hasta el exceso, corrigiendo y manipulando exageradamente sus semblanzas; de esta manera acaban plasmando otro cuerpo que se forja sobre el original hasta convertirse en simulacro. El cuerpo, entonces, se vuelve en espacio de transgresión de fronteras, un territorio donde impera la ambigüedad y donde no es posible fijar los límites. Se asiste, así, a un uso estratégico de la semiótica del cuerpo como instrumento que permite cruzar múltiples fronteras, no solo entre Puerto Rico y República Dominicana, sino a través de una desterritorialización de concepciones, prácticas y quehaceres que plantean nuevos retos.

La figura del travesti masculino logra profundizar este sentido de infracción de los márgenes: no solo pretende parecerse a una mujer, sino que enfatiza, hasta la caricatura, los rasgos de la feminidad, desde los eróticos hasta los psicológicos. Pero su verdadero secreto-arguye Severo Sarduy- es lo que guarda detrás del disfraz, lo que no evidencia, sino que esconde, porque el travesti no copia, simula, "pues no hay normas que invite y magnetice la transformación, que decida la metáfora" (Sarduy, 1982, 13). Así, la imagen que proyecta de su cuerpo proyecta a la vez un espacio construido por la inexistencia del ser, 
logrando demostrar que el género, como la identidad sexual, es una ilusión, una construcción, una máscara, un travestismo. Al simular, y no al copiar, el travesti proyecta lo que simula sin dejar de mostrar lo que es, porque es, en realidad y al mismo tiempo, ambas cosas. Por esto ocupa un lugar bidimensional, ya que hace de la dualidad su marca diferencial.

En el caso del/la cantante de bolero Selena, la dualidad es aún más explícita: el nombre artístico escogido -Sirena- lo hace patente, alertando sobre la duda de si cumplirá o no con las expectativas. Mujeres-pez, las sirenas con sus músicas atraían a los navegantes y, al atraparlos en sus redes, devoraban a los imprudentes. Precisamente como ocurría con los seres mitológicos, también el/la joven bolerista sorprende al lector con su actuación final que, una vez más, desmantela los roles atribuidos y revela el poder que tiene el travesti, ya que, en sus manos está la posibilidad de desprenderse de una realidad dada para formar otra, la propia.

La diégesis es bastante sencilla: un quinceañero huérfano, pobre y negro, tiene como futuro un porvenir de miseria y de vida en las calles. Gracias a su voz especial, Martha Divine, travesti ya mayor y "con sangre de empresaria" (Santos-Febres, 2000, 11) lo descubre y decide sacarlo del barrio marginal donde ejercía su profesión sexual para convertirlo en un travesti cantante de boleros. Al ser prohibido en Puerto Rico hacer trabajar a los menores, Martha Divine decide llevar al joven a la República Dominicana, buscando a través de algunos empresarios del turismo local un contrato para que pueda exhibirse en los hoteles de lujo de la vecina isla.

Para la "madrina" Martha, Sirena es el medio que puede permitirle alcanzar su deseo primordial: recoger el dinero suficiente para la operación de cirujía con la que, definitivamente, podría cambiar de sexo. Para Sirena, en cambio, Martha es el instrumento que le puede facilitar la escalada social. Sin embargo, la realidad aplasta los sueños de ambas: después de esperas y aplazamientos de citas en tierra dominicana los dos travestis se dan cuenta de que lo prometido es solo una ilusión.

La acción de los dos personajes principales puede desarrollarse gracias a la presencia de otros sujetos que refuerzan la idea de movilidad espacial e identitaria. Entre ellos, la figura de Contreras, el personaje que trabaja de mediador entre la "alcahueta" Martha Divine, que quiere vender los espectáculos de Sirena, y Hugo Grauber, el empresario dominicano dueño de una cadena de hoteles de lujo a los que acuden cantidades de turistas extranjeros, además de ser el dueño del hotel "El Conquistador", cuyo nombre es explicativo.

Contreras ejerce el rol de quien debería satisfacer las dos partes para que lleguen a un acuerdo, el cual nunca se estrechará. Su manera de operar manifiesta, abiertamente, ambigüedad y engaño: cada día aplaza la cita de la supuesta firma del contrato para las exhibiciones del/la bolerista sin revelar la real motivación de la prórroga, pues de hecho encubre las verdaderas intenciones 
de Grauber que, al haberse quedado encantado con el "demo-show" de Sirena, decide organizar en su casa una serie de exhibiciones privadas del/la artista. El real objetivo del empresario es tener relaciones sexuales con Sirena, ya que siente por él/ella una profunda atracción. Sirena, por su parte, ve en la propuesta una oportunidad mayor de ganancia, lo que hace que no revele el secreto a su madrina. Todos, entonces, recurren a la trampa y al engaño, todos enmascaran sus verdaderas intenciones y sus verdaderas identidades.

En el caso de Grauber, su comportamiento enfatiza aún más la dificultad de establecer una identidad sexual fija. Aunque este millonario, junto con sus amigos empresarios, ocupa un posición de poder, vive también su forma de marginación, puesto que es un hombre cuya colocación lo obliga a esconder sus preferencias sexuales. Aún peor, perteneciendo a la esfera de influencia que decide y perpetúa el orden establecido, se le hace perentorio esconder su fragmentación interior. Desde la adolescencia, Grauber creció siendo un hombre inseguro de su propia identidad; en su batalla interna nunca logra encontrarse a sí mismo y anhela "sentir aquella sensación de cuerpo distendido, doble" acostándose con hombres y mujeres (Santos-Febres, 2000, 135). Su matrimonio con Solange no es más que una fachada tras la cual sofoca sus reales deseos y que le permite participar en el mundo velado de su país.

En el ambiente enmascarado de los hoteles lujosos y turistas extranjeros, Hugo Grauber intenta buscar y a la vez esconder, esa identidad doble que todavía no entiende y no acepta. Solo el encuentro con Sirena lo empuja a resolver su "refractariedad del deseo", superando aquella dimensión de la subjetividad que no proporciona identidad, sino división (De Lauretis, 2000, 163).

En fin, todos los sujetos de la narración actúan para realizar sus intereses, todos quieren tener su beneficio: "Tan chiquita y tan capaz de sacarle los ojos a su propia madre" (Santos-Febres, 2000, 236), reflexiona Martha cuando no ve regresar a Sirena al Hotel. Todos, de una forma $u$ otra, enmascaran su verdadera identidad.

De igual manera, a todos les falta estabilidad, pues en la novela hay varios cambios de roles, alianzas que se rompen para estrechar otras con otros, con el único objetivo de sacar el mayor provecho para cada uno. Sirena quiere incorporase al mundo del glamour como símbolo de la superación del contexto de probreza del que proviene. Por esto acepta la propuesta de su empresaria Martha con la esperanza que pronto "se convertiría en la estrella de un show para hoteles de cuatro estrellas. Tendrá un vestidor y luces confeccionados con las mejores telas que se prestarán para el simulacro" (12).

Para Sirena, la condición de marginalidad ha surcado su existencia, desde los primeros años de vida. Solo la abuela, de toda la familia, ha constituido un punto de referencia sentimental y le ha transmitido la determinación a ser fiel a lo que uno siente. Al morirse esta "de tanto limpiar casas de ricos, no había nadie más que velara por él" (6). "Nadie más de mi familia ha querido sacar 
la cara por mí. Así que la tengo que sacar yo solito" (88). Entre un lugar de crianza, comparable solo con un círculo del infierno, y la calle, Selena prefirió la calle, escenario de gran releve en la narración, y de este modo, hace hincapié en la idea de movilidad y errancia de los sujetos que en ella transitan.

En la calle encuentra a Valentina Frenesí -otro nombre sugerente- un drogadicto travesti que se convierte en una verdadera madrina para Selena y que lo lleva a vivir a su casa. Para Valentina, Selena siente cariño, pues es la única que se ha hecho cargo del joven sin pedir nada a cambio. Más bien, ella lo/la "educa" y lo/la instruye en el arte de ser mujer, aconsejándole aprovechar su juventud y su belleza natural como hombre, y no como mujer, ya que así lo/ la solicitarán más los clientes: "Aún no, nena, tú de bugarroncito tienes más oportunidad. Eres bello. Entre tanta basura, encontrarse algo así de lindo es un milagro"7 (Santos-Febres, 2000, 79).

Como se puede notar, Valentina se refiere a él/ella como una nena, que es bello; en este modo, desde el comienzo, se subraya la ambigüedad sexual que consituye el misterio y el éxito de Selena. Al trabajar como sujeto que se prostituye con los hombres, o sea desempeñando un papel que tradicionalmente está relacionado con las mujeres, Sirena empieza a quebrantar los esquemas fijos y a definirse de otra manera.

Santos-Febres lo enfatiza por medio de recursos lingüísticos con los que expresa la sexualidad del personaje. Las referencias hacia el sexo masculino y femenino apuntan a matizar la hibridez del sujeto y su multiplicidad, destacando la posibilidad de un cruce génerico que lo ubica en una redefinición de la relación entre los géneros, puesto que lo que termina estableciendo es un continuum entre ambos géneros y sexos y, por consiguiente, una ruptura con la concepción binaria planteada, y una salida de la escala social establecida (Rubin, 1989, 159-161).

Madrina al pie de la letra, Valentina Frenesí quiere el bienestar y éxito de su ahijada dentro de su ambiente, por esto le brinda consejos para que pueda ejercer, sin muchos riesgos, su nueva profesión en el barrio marginal de Santurce. Sin embargo, a pesar de las recomendaciones, Sirena no puede evitar los peligros de la calle y durante una noche de trabajo es violada por un hombre blanco y rico.

La secuencia con la que ocurre la brutalidad resume el abuso de los poderosos hacia las personas que se prostituyen para sobrevivir. Santos-Febres no se detiene en largas descripciones, con pocos detalles logra informar al lector que "aquella noche maldita, se paró frente a ellos el Mercedes gris, con cristales ahumados. De aquel carro salió una blanquísima mano sosteniendo bastantes billetes" (Santos-Febres, 2000, 83-84). Sirena sube y de él/ella durante toda la noche no se sabe nada más. Horas después Valentina la encuentra "con

$7 \quad$ El énfasis es mío. 
el calzoncillo ensangrentado" (Santos-Febres, 2000, 85) para luego llevarla al hospital. De ahí la promesa que nunca más permitiría que la penetraran.

La muerte por sobredosis de su madrina deja nuevamente desamparado al joven. Pero por poco tiempo, ya que Martha Divine, al escucharlo cantar, decide hacerse cargo de Selena convirtiéndose en su nueva madrina-empresaria: "caminó hasta donde estaba el muchacho, lo invitó al bar, a tomarse una Coca-Cola. Le ordenó comida, lo ayudó a romper vicio, lo vistió de bolerosa" (Santos-Febres, 2000, 11).

Por su nueva madre, Sirena empieza a sentir estima y respeto, pues si Valentina representa el vínculo afectivo, Martha representa la posibilidad de supervivencia, puesto que le promete el éxito ante la sociedad alta dominicana, trampolín para llegar a la meta final: Nueva York. Un éxito que ante todo responde al deseo de la nueva madrina de ganar dinero y satisfacer su gran anhelo de operarse para cambiar de sexo: "Ayudando a la Sirena se ayudaba a ella; ayudando a esta joyita que le caía del cielo, iba al fin a reconciliarse con su propio cuerpo" (Santos-Febres, 2000, 21), ya que "operarse no es lo mismo que vestirse [...] Quitarse la ropa y verse, al fin, de la cintura para abajo, igual que de la cintura para arriba. [...] Al fin, poder descansar en un solo cuerpo" (SantosFebres, 2000, 19). En varios momentos Martha Divine hace patente su crisis de identidad, ya que no soporta vivir en un cuerpo que no corresponde con su identidad subjetiva, al contrario de Sirena que vive sin tormento su "dislocación". Para ambos, vender espectáculos se convierte en el instrumento para alcanzar sus objetivos.

La transformación del quinceañero en un travesti talentoso ocurre rápidamente ${ }^{8}$, sin embargo, las decripciones sobre la preparación antes de los espectáculos para que Sirena se presente al público como mujer "ultrafemenina", seductora y sofisticada, son detalladas minuciosamente. El relato informa sobre todos los procedimientos de la transformación exterior para borrar las facciones masculinas y redefinir al/la cantante como femme fatale. Este es el gran reto de Martha Divine. $Y$ al vestir al jovencito, nada lo deja al caso: trajes largo color perla donde "a la altura del muslo, le surgía una profunda grieta que destapaba la pierna derecha. Esa iría enfundada en medias traslucidas de un tono levemente más oscuro que la piel de la Sirena" (Santos-Febres, 2000, 28). Vestimenta y maquillaje permiten construir una imagen simulacro que responde a los cánones de la feminidad con base a los parámetros sociales y a los deseos masculinos.

El arte del vestirse y del travestirse, es sabido, está directamente vinculado con el arte de la seducción que el cuerpo vestido/travestido ejerce sobre los demás, satisfaciendo la imagen que otros quieren tener de nosotros. El procedimiento que va "del cuerpo desnudo al cuerpo revestido" implica,

$8 \quad$ La repentina transformación del protagonista recuerda la modernización vertiginosa de la isla que se puso en marcha con la operación "Manos a la Obra" en la década de los 1940. 
en sustancia, la dimensión pasional del vestirse, una sensación de gustar y gustarse que conduce a una forma de manipulación del cuerpo vestido que se plasma sobre la imagen que los otros tienen, o se piensa que tienen, del travesti (Greimas, 1990, 58). Se trata de una vestimenta que se basa en una estética del exceso: exageración de lo femenino, pero también de lo "pobre" y de la violencia, puesto que la figura del travesti representa al Otro, pero a la vez a sí mismo dejándose ocupar por el Otro en un acto de auto-realización, con el fin de subvertir su significado en el contexto cultural. Instiga, así, de manera clara, una crisis de categorías. La seducción consiste en hacer creer al Otro que es y sigue siendo el objeto del deseo sin por esto caer en esta trampa. Sirena lo aprende pronto y seguirá este precepto hasta el final cuando acepta tener una relación sexual con Grauber.

Paralelamente a las vicisitudes de Sirena y Martha, la novela desarrolla una segunda historia que narra la vida de dos jóvenes dominicanos, Leocadio y su amigo Migueles. En esta historia, Leocadio funciona como "doble" de Sirena, su consciencia velada. Leocadio y Migueles comparten el mismo sueño ilusorio de ir a Puerto Rico, isla que para los dominicanos representa un primer paso para acercarse al sueño americano. Afeminado del campo, Leocadio conoce a Migueles que pronto se convertirá en una suerte de hermano mayor que lo inicia a la vida, al amor y al trabajo en el Hotel Colón donde acude el turismo gay.

A pesar de no ser el protagonista de la novela, Leocadio ocupa uno de los capítulos más importantes ya que, por medio de sus meditaciones sobre la identidad y el poder, se derrumban las distinciones binarias para dar espacio a nuevos planteamientos. Cuando el adolescente empieza a descubrir el mundo de su identidad homosexual no se niega a aceptarlo, ni actúa para disfrazarse de lo que no es. Por esto, además de funcionar como alter ego de Sirena, Leocadio de alguna manera representa el sujeto del futuro ya que descubre cómo lo femenino y lo masculino pueden estar cargados de autoridad; al ser consciente de esto, no encierra su identidad homosexual en la marginalidad, más bien durante un baile con Migueles reflexiona sobre los paradigmas que imponen la elección sexual:

Uno hombre, el otro mujer, aunque puede ser el más chico, que no necesariamente sea un hombre el más fuerte ni el más grande que el otro, sino el que dirige, el que decide, el que manda. Hay muchas maneras de mandar, muchas formas de ser hombre o ser mujer, una decide. A veces se puede ser ambas sin tener que dejar de ser ni lo uno ni lo otro (Santos-Febres, 2000, 258).

Podríamos considerar esta cita la síntesis de la búsqueda de una configuración identitaria de sexo y de género, ya que con ella se plantea un mundo donde los roles sexuales pueden expresarse y moverse libremente, superando 
el rigor de la estaticidad y confiriendo al nomadismo un estatus de primer nivel en la constitución identitaria ${ }^{9}$.

Mientras Hugo, al tratar de negar públicamente su homosexualidad, hace patente el poder del sistema patriarcal del Caribe que él mismo encarna, Leocadio pone en relieve que el arriesgarse a ser una u otra cosa es posible y aceptable, siempre que sepamos manipular las definiciones correctamente. Su posición social hace menos díficil esta aceptación, por el contrario para Grauber desmantelar el armazón oficial significa poner en tela de juicio los esquemas y las reglas sobre los que se fundan también sus privilegios.

La acción de Hugo y Leocadio cuestionan el rol activo que se debe tomar dentro de una relación, el de mujer o el de hombre, dado que ambos están transformando su identidad. De igual manera, ambos hacen un intento de alterar las reglas sociales, solo que para el primero la infracción es algo que debe enmascararse y cubrirse para sobrevivir en cuanto clase, mientras que para el segundo el ambiente velado es una imposición que, de algún modo, se puede ultrajar. Esta lucha entre esconder, crear y negociar su identidad es la línea conductora de la novela. Los distintos sujetos que pueblan la narración confunden sus rasgos y atributos sexuales, masculinos en femeninos y viceversa.

De esta forma se elabora una nueva conceptualización del sexo entendido no en cuanto unidad, sino en cuanto diálogo y proceso en devenir. Esto se hace posible, a nivel textual, mediante una ornamentación lingüística que desplaza al lector en el espacio del texto, así como por medio de un lenguaje que se mezcla con el registro popular de la música y del bolero, dando lugar a un híbrido también desde el punto de vista del género literario.

Las dualidades de Sirena son las que seducen a Grauber y también son el secreto de su éxito cuando se exhibe. La aparente fragilidad del/la cantante se distancia de su voz decisiva y fuerte; lo mismo ocurre con su cuerpo enmascarado de mujer delicada que derrumba esta apariencia una vez que lo ven desnudo: "La verga de Sirena era inmensa, un poquito grotesca por la falta de proporción que guardaba con el resto del cuerpo" (Santos-Febres, 2000, 48). Este es el secreto de Selena, y Hugo, como los navegantes que no supieron resistir al canto de las sirenas, queda atrapado en su red: "Hugo se ahoga, se muere de ardor [...] se deja ir, cierra los ojos y se deja ir [...]. Ya no lucha, se entrega" (Santos-Febres, 2000, 210).

Es ahora que Sirena revela toda su ambigüedad. Como es peculiar del travesti, el bolerista evidencia su poder de desprenderse de una realidad dada para formar otra, la propia. Selena engaña al lector durante toda la novela haciéndole creer que quiere ser una mujer, pero al final da peso a su cualidad

$\overline{9}$ En este capítulo -el XLVIII- se destaca la influencia de las teorías de Judith Butler en la autora puertorriqueña, así como los postulados básicos del postestructuralismo. 
biológica y es él quien penetra a Grauber, cumpliendo con la promesa hecha a su madrina Valentina.

Toda la novela está atravesada por constantes cruces de género, la mayoría de los cuales están disfrazados ya que no es fácil desmantelar los esquemas establecidos. Sin embargo, el constante "atravesamiento genérico" pone en luz la imposibilidad e inutilidad -como en el caso de Leocadio y Miguelesde fijar una identidad específica, lo que refuerza la idea del movimiento como rasgo peculiar de toda identidad.

\section{Nadie me verá Ilorar}

La novela de Cristina Rivera Garza tiene múltiples posibilidades de aproximación, ya que se trata de un texto complejo en el que los diversos aspectos que emergen descansan en un trasfondo histórico determinado: el último periodo del porfiritato, el proyecto de modernización de México y los años de los distintos gobiernos desde del triunfo de la Revolución mexicana, hasta el gobierno de Adolfo Ruiz Cortinez que termina en 1958, fecha en que, según los expedientes consultados en el manicomio de "La Castañeda", muere la paciente que ha inspirado la creación de la protagonista de la novela.

El relato oscila entre el lado luminoso de la modernidad, sus alcances, sus edificios moldeados sobre el estilo francés, el alumbrado público, etcétera, y el lado más oscuro de los barrios marginales, los dormitorios públicos, los prostíbulos, el manicomio. Lugares en los que iban a parar todos los individuos que no respondían a la consigna de "Orden y progreso" promulgada por el gobierno de Porfirio Díaz, es decir, todos sujetos no funcionales a la construcción de la identidad mexicana que se pretendía plasmar.

En la narración se cuestiona el discurso de la Historia oficial para explorar los márgenes de otra historia, la de los sujetos ignorados y privados de los privilegios de la ciudadanía, los sujetos considerados como un obstáculo para el camino modernizador del país. Además, se disuelven las fronteras genéricas entre historia y ficción para dar espacio a las historias "menores" o ficcionalizadas. Asimismo, el relato derrumba las clasificaciones netas entre heterosexualidad, homosexualidad y transexualidad presentando personajes que transitan en territorios sexuales diferentes y que, a través de su movilización, logran distanciarse de la noción tradicional de identidad en tanto rígida clasificación que funciona como instrumento del poder.

La movilidad identaria y su resistencia a la reglamentación del comportamiento femenino es, por tanto, uno de los aspectos centrales de la novela puesto que la obra hace hincapié en la relación de fricción que existe entre los discursos que construyen la identidad social, racial, de género, de preferencia y comportamiento sexual, pero a la vez indaga sobre el diálogo y la negociación que se establece entre los diversos aspectos. 
La transgresión de la distintición entre géneros de escritura se combina con la transgresión de la escritura sexogenérica, rasgos, estos, que son peculiares de la producción de Rivera Garza; en Nadie me verá llorar los diversos protagonistas buscan una alternativa a su posición de desigualdad mediante la exploración de una sexualidad alternativa, fuera de los comportamientos sociales reconocidos, lo que produce, como consecuencia, marginación y segregación.

Los excluidos del gran proyecto nacional -masculino y patriarcal- son los que se niegan a los preceptos de modernización del porfiriato sobre el cuerpo y la salud, que se fundamentaba sobre supuestos conocimientos científicos y médicos con los que se pretendía controlar la población. Quienes salían de los postulados establecidos estaban condenados al aislamiento, empujados hacia los márgenes de la sociedad que se "limpiaba", de esta forma, de prostitutas, drogadictos y enfermos mentales, pero también de pobres, vagabundos, opositores y rebeldes.

Así, mediante una serie de estructuras de reclusión, se garantizaban las fábricas de cuerpos sometidos y ejercitados, cuerpos "dóciles" (Foucault, 1975), vigilados y castigados por no participar en los planes definidos. Cuerpos sometidos y catalogados por el Estado, ya sea por su condición social o de salud, cuya sumisión no deja de ser contestada por una constante tendencia a la abolición de la disciplina con la que se pretende sujetarlos.

Para representar las diversas piezas que componen este mundo, Rivera Garza recurre a la fragmentariedad y a la ruptura de las fronteras, a la discontinuidad y la manipulación narrativa, a la falta de linealidad cronólogica, elementos que han llevado a definir Nadie me verá llorar como una novela posmoderna. En efecto, la obra no se somete a reglas establecidas en su proposición de reinventar la historia y las historias de sus personajes que infringen las fronteras geográficas, físicas, psíquicas y sexuales mediante un constante juego con el lenguaje que avala la movilidad de la identidad y del género literario. La autora emplea una pluralidad de registros discursivos, la intertextualidad y la parodia como instrumentos para incursionar y explorar un mundo complejo, desde el cual se resaltan los fuertes contrastes entre los dominantes y dominados, entre los que imponen reglas y comportamientos y los que a estos se resisten.

El escenario principal de la novela es "La Castañeda", manicomio inaugurado por Porfirio Díaz en el contexto de las celebraciones de la Independecia (1810-1910), y donde se recluyeron, sin distinción, a indigentes y alcohólicos, dementes y prostitutas, anarquistas y drogadictos. Es decir, todos los individuos considerados negativos para el proyecto de progreso del país. Se trata de una institución de alto valor simbólico, ya que allí se aglutinaban a todos los que no cabían en la estructura social planteada. Para ser internados, en muchos casos, eran suficientes los antecedentes familiares; asimismo, con igual "facilidad", se elaboraban diagnósticos que tenían que ver más con la moral que con la ciencia, de ahí la presencia de varios expedientes que diagnosticaban 
una "locura moral" que afectaba principalmente a las pacientes femeninas. La infracción del respeto del rol de género, entonces, era motivo de diagnóstico de locura moral. El ambiente está recreado en pocas líneas descriptivas con las que se traslada al lector a un espacio donde reglas e infracción de las reglas marchan juntos:

El reloj de la fachada principal de la institución indica que son las seis y treinta y siete de la tarde.

El manicomio tiene veinticinco edificios diseminados en 141,662 metros cuadrados. Dentro, protegidos por altos muros y rejas de hierro, los locos y los castaños proyectan sus sombras sobre lugares apartados del tiempo. El manicomio es una ciudad de juguete (Rivera Garza, 1999, 32).

La reconstrucción de "La Castañeda", al igual que la construcción del personaje central de la narración, Matilda Burgos, no son fruto de la imaginación de la autora, por el contrario se nutren de datos reales e investigaciones meticulosas ${ }^{10}$ sobre los que radica la diégesis. Como Rivera aclara al final de la novela, el personaje de Matilda es la recreación de Modesta Burgos, cuyo expediente encontrado en los archivos del manicomio constituye la fuente de inspiración de la protagonista de Nadie me verá llorar.

El capítulo final donde se incluyen los documentos del expediente de Modesta Burgos, confiere a la narración también un carácter testimonial: "Los documentos que se transcriben en el capítulo 8 son copia fiel de los escritos de Modesta Burgos L., la enferma que hablaba mucho. Los guiones entre palabras le pertenecen a ella" (Rivera Garza, 1999, 208). Así, la historia y la ficción ceden lugar al testimonio real de los acontecimientos, rompiendo nuevamente barreras y fronteras entre géneros literarios.

Por medio de digresiones analépticas, registros distintos, pasajes caracterizados por un lenguaje esquizofrénico, Rivera Garza logra devanar un discurso en el que las distintas voces, y conciencias, se alternan con la voz del narrador, dando vida a una polifonía y pluralidad de focalizaciones que desestabiliza al lector, acercándolo al mismo tiempo a otros mundos y otros planos narrativos donde la identidad, en sus inversiones y erosiones, se mueve en busca de otra identidad que haga posible encontrar una respuesta al deseo. Paralelamente interviene, en dos capítulos, la voz de un narrador heterodiegético que contextualiza al lector en un tiempo histórico.

La novela narra la historia de Matilda Burgos, interna del manicomio; su vida y su personalidad van componiéndose por medio de la focalización de Joaquín Buitrago, fotógrafo oficial del manicomio, que cree reconocer en Matilda a una prostituta que conoció -y retrató- cuando fue fotógrafo del burdel "La Modernidad". La búsqueda para descubrir la verdadera identidad de la mujer lo empuja

10 La investigación sobre La Casteñena fue objeto de la tesis doctoral de la autora, "The Master of Streets: Bodies, Power and Modernity in Mexico, 1867-1930", defendida en la Universidad de Huston en 1995, como refiere Ruffinelli $(2008,33)$. 
a buscar el expediente de la enferma, ahí empieza un trabajo casi obsesivo de investigación sobre los orígenes del pueblo de donde ella procedía y los antecedentes de su familia. Logra así componer una historia en la que se alternan las vivencias de la protagonista contadas por ella misma, y los escritos que Matilda y otros internos de "La Castañeda" redactan dentro del manicomio, "un lugar tan lejos de la historia y tan lleno de historia” (Rivera Garza, 1999, 33). A esto se suman las vidas y los quehaceres de otros personajes cuya presencia en el relato coopera a delinear la personalidad de la protagonista.

Las historias de Matilda y Joaquín se entrelazan con la historia de dos anarquistas, Diamantina Vicario y Cástulo Rodríguez, figuras que les cambiarán a ambos, aunque de manera distinta, su vida y sus percepciones del mundo. A través de la mirada -y de la lente de la cámara- de Buitrago se narra cómo Matilda Burgos, india de Papantla, desarrolla una esquizofrenia al verse obligada a adoptar una identidad que no sabe cómo asumir. Huérfana, llega a la Ciudad de México para vivir con su tío Marcos Burgos, quien en 1890 se graduá de médico con la tesis "La ciudad de México ante los ojos de la Higiene". Al conseguir el título "desarrolló una fe ciega en las posibilidades abiertas del futuro, en el progreso de la nación” (Rivera Garza, 1999, 102).

La figura del tío representa el prototipo del hombre que cree ciegamente en los principios de "Orden y progreso" que propagaba el porfiriato. La llegada de su sobrina Matilda constituye para él una posibilidad de experimentación de sus teorías; en el intento de convertirla en una "buena ciudadana, una muchacha decente, una mujer de buenas costumbres" (Rivera Garza, 1999, 100), Marcos Burgos pretende erredadicar de ella los supuestos defectos genéticos heredados de su padre alcohólico y moldearla sobre la base de las nuevas posibilidades que ofrece la modernidad. De esta manera, pone en marcha un proceso "educativo" con el cual intenta cancelar el pasado de Matilda, un pasado poblado por mexicanos "salvajes, primitivos, obtusos y tercos" (Rivera Garza, 1999, 107) para poder ir construyendo una nueva vida según los dictámenes del orden y el progreso.

Encarnación de la ideología positivista, el médico apuesta por el método científico como solución de todos los problemas sociales, método que él sintetiza en los resultados logrados en su tesis de grado donde "demuestra" que la higiene y la educación pueden transformar a las capas sociales más bajas y elevarlas al rango de buenos ciudadanos. En su visión, la higiene debía ser no tanto un derecho, sino un deber ciudadano, ya que "todas las patologías estaban directamente relacionadas con la falta de higiene tanto física como mental del populacho" (Rivera Garza, 1999, 106).

Sus lecciones de Higiene ponen en evidencia la necesidad de ordenar, fijar límites y reglas dentro de las cuales los individuos -y las mujeres de manera especial- pueden considerarse parte del gran proyecto social de transformación; en otras palabras, los preceptos de la higiene social están 
directamente vinculados con el derecho de ciudadanía: dependiendo de si se siguen, o no dichos dictámenes, se puede conferir o quitar la ciudadanía. Enumera Marcos Burgos:

Mantenerse continuamente ocupado para preservar la higiene mental [...].

Evitar el uso de cosméticos y de perfumes. Los primeros dañan la piel, los segundos causan neurastenia y otras malformaciones nerviosas [...].

Procurar bañarse hasta tres veces al dia durante los periodos menstruales [...].

Las mujeres decentes se bañan todos los días antes de las seis de la mañana, siempre (Rivera Garza, 1999, 103).

La idea de higiene social se trenza con el discurso de la moral para componer un cuadro de normas que será utilizado por el poder para estigmatizar los comportamientos de Matilda.

El encuentro con Diamantina Vicario y Cástulo Rodríguez, dos revolucionarios sostenedores de la causa obrera, es el detonador que hace que Matilda decida renunciar a las comodidades y escoja un nuevo camino donde experimentarse y configurar su identidad a través de búsquedas y desplazamientos, sin imposiciones. Diamantina Vicario es, además, el punto de contacto entre los recuerdos de Matilda y Joaquín, ya que fue la primera mujer de ambos.

Cabe subrayar que la personalidad de la protagonista va configurándose en la medida que entrelaza su existencia con otros personajes: Joaquín Buitrago y el doctor Eduardo Oligochea que se encarga de ella en el manicomio, pero también, entre otros, Cástulo y Diamantina, de quien Matilda se enamora perdidamente, Madame Porfiria, responsable del burdel donde Matilda irá a parar, y Ligia, la otra Dimantina, como la apoda Matilda, la prostituta que encuentra en el prostíbulo "La Modernidad". Asimismo, otros sujetos aportarán al desarrollo del personaje central, como ocurre con el geográfo estadounidense Paul Kamàk, llegado a México con el sueño de abrir una mina en la zona de San Luis Potosí y con quien Matilda entretuvo un breve romance. A través de estas relaciones y perspectivas se empieza a establecer la realidad del personajes y del texto, y se va descubriendo que la movilidad identitaria es uno de los pilares de la narración.

La relación que estrecha con Cástulo y Diamantina constituye el triángulo que le permite conocer que "La felicidad consiste en besarse por placer" (Rivera Garza, 1999, 154); sin embargo al decidir Dimantina volver a incorporarse a la lucha abandonando la ciudad, la relación con Cástulo ya no tiene sentido: solos, "se convirtieron en puntos extremos de una línea recta y no se volviveron a tocar" (Rivera Garza, 1999, 165). Ya Matilda no vuelve a ser la misma, su vida de ahora en adelante pasa por numerosas vicisitudes que la transformarán en lo hondo de su ser, haciéndole adquirir un nueva consciencia de de sí misma y de su manera de enfrentarse al mundo que la rodea. 
Obligada a trabajar para garantizarse la subsistencia, encuentra un empleo como obrera en una fábrica, experiencia que refuerza sus convicciones sobre la defensa de los derechos de los trabajadores. Por esta razón la despiden, por el solo hecho de ocuparse de una compañera de trabajo que se sintió mal y que necesitaba ser llevada al hospital. En la calle, sin dinero ni perspectivas, no le queda más que el mundo de la prostitución, la cual ejerce en una casa de citas llamada "La Modernidad", cuyo dueño -un travesti- lleva el nombre elocuente de Madame Porfiria.

La prostitución se convierte en un instrumento con el que logra afirmar también una suerte de libertad sexual, y es en el prostíbulo donde logra rechazar la heterosexualidad como norma única de comportamiento. Es allí que establece una relación con otra mujer, Ligia, a quien pone el apodo de "Diamantina" y que será su amante, su amiga y confidente. Es con ella que infringe las reglas comportamentales y que descubre el placer, el erotismo y el cuerpo en tanto receptor, y no solo productor, de placer. En otras palabras, con Diamantina, Matilda logra derrumbar las construcciones por las cuales el sexo no es más que una práctica reguladora y de control (Foucault, 1977). Con ella decide llevar a la escena -en el burdel- la relectura paródica de Santa, de Federico Gamboa, obra paradigmática de la visión masculina de la sexualidad femenina. Contraria a la domesticación de las mujeres, Matilda ironiza la postura de Gamboa -"iAy, pobre embajador Gamboa, tan cosmopolita y tan falto de imaginación!" (Rivera Garza, 1999, 145)- y desarticula, mediante una nueva representación de la obra, los ejes oficiales de los roles sexuales. De este modo, se proyecta una nueva perspectiva de la identidad de género que pone al centro la elección, el deseo, la necesidad y la legitimidad de conseguirlo.

En el proceso de relectura de Santa, la protagonista adquiere el nombre de "La Diablesa", viste trajes masculinos y actúa desplazando no solo la centralidad masculina, sino también la cuestión de género entendido como hecho natural. En la crítica de los roles sexuales, Matilda/Diablesa se transforma en un ser andrógino -"Matilda se convirtió en un hombre de frac" (Rivera Garza, 1999, 147). Los disfraces escénicos la hacen sentir bien también fuera de la escena, así que la Diablesa "comienza a tener fama de andrógina" (Rivera Garza, 1999, 149).

Las páginas de esta obra mexicana son leídas con atención y sarcasmo, la representación de Santa como mujer incapaz de entender los avances de la gaditana o de rechazar con asco cualquier comportamiento fuera del rol establecido, despiertan risa y empujan a ultrajar la visión propuesta: "leyeron el pasaje juntas, no sólo no pudieron evitar las carcajadas sino que además hicieron el amor sobre las páginas del libro" (Rivera Garza, 1999, 143). Ligia y Matilda disfrutan del sexo y de su lesbianismo, afirmando así la legitimidad del placer, la elección de sus deseos y la búsqueda de su satisfacción, y quebrantando el rol de víctimas que la obra de Gamboa confiere a la mujer. 
El desarrollo del amor lésbico y la nueva consciencia identitaria constituye un desafío a las normas morales y sociales. Es allí donde la protagonista se siente bien, donde adquiere fuerza y determinación y donde abandona los temores de la jovencita que de Papantla llega a la capital para convertirse en una mujer con características bidimensionales: una mujer andrógina, en cuyo cuerpo se inscribe simbólicamente el sentido de lo femeino y masculino. Se conforma, así, su masculinidad femenina, que expresa con actos transgresores y con el claro rechazo de adaptarse al ámbito tradicional. Matilda reúne en sí una dualidad fundamental -vestigio incierto de lo otro (Kristeva, 1991, 60)- una fusión en sí misma que pone acento en la noción de frontera identitaria donde prima el deseo, el goce de lo incierto, más allá de los cánones y esquemas. Seres sexualmente transgresivos, los androginos, al igual que los travestis, evidencian en un solo cuerpo-personaje la presencia del otro en uno, o sea el ser uno en la otredad (Kulawik, 2009, 279-280). De esta manera, Rivera Garza da origen a una escritura que imagina el cuerpo, lo construye y diversifica, ofreciendo al lector una simbolización del deseo, cuyas pulsiones se anudan al lenguaje.

Desde este punto de vista, la protagonista da lugar a una poética del cuerpo ajena a las convenciones y que coopera a la conceptualización de una masculinidad sin hombres donde no hay una subversión del poder masculino ni una posición en contra de este, sino que se dan las espaldas a los poderes tradicionales y se actúa a partir de un nuevo espacio donde no prima el heterocentrismo, más bien se expresa otro modo de vivir el género (Halberstam, 2008 , 9) haciendo sucumbir los constructos identificatorios que separan lo masculino de lo femenino.

En este sentido, la frase "Nadie me verá llorar", que Matilda repite en varios momentos de la narración, destaca su alejamiento de un comportamiento considerado femenino por excelencia. El llanto siempre ha sido catalogado como acción estrechamente relacionada con la mujer, pues es solo a ella a quien le es permitido llorar. Por esto Matilda evita llorar frente a la gente, ante la cual enseña solo su rostro de fuerza, ocultando sus debilidades, fragilidades y vulnerabilidad.

Pero cuando la nueva Diamantina la deja y Matilda queda de nuevo sola, sufre profundamente su condición. No llora frente a los demás, pero decide aceptar la propuesta de seguir a Paul Kamàk, a quien había conocido en "La Modernidad", para ir al desierto de San Luis Potosí. La revolución está en progreso; sin embargo, para ellos no existe el mundo externo, solo existe una realidad hecha de silencios y ganas de borrar todo el pasado. El entorno no existe, solo existe el proyecto. Al no encontrar seguidores, la desilusión de Kamàk lo llevará al suicidio. Frente a esa nueva pérdida, Matilda reacciona dando fuego a su casa y sus pertinencias, buscando crear un vacío en su memoria, una anulación del pasado y del tiempo. Despierta así en un hospital en San Luis Potosí en donde le diagnostican esquizofrenia, motivo por el 
que la trasladan a "La Castañeda". En el expediente No. 6353 relativo a su caso, se leen las motivaciones de su ingreso:

Matilda Burgos L., Papantla, Veracruz, 1885.

Sin profesión. Soltera. Católica. Constitución regular. Desarrollo precoz durante la niñez. Padre alcohólico y madre asesinada. [...] Prueba de Wasserman negativa. La interna es sarcástica y grosera. Habla demasiado. Hace discursos incoherentes e intermibables acerca de su pasado ${ }^{11}$.

A pesar de resultar negativa a la prueba de Wasserman, Matilda está encerrada por manifestar, como comportamiento disconforme a las reglas sociales, una fuerte necesidad de hablar, a la que, durante los años, alternará con grandes momentos de silencio. El manicomio es, para una mujer desprovista de sus derechos civiles, "el lugar donde se acababa el futuro" (Rivera Garza, 1999, 26) y en donde Matilda, en lugar de "curarse", radicaliza los síntomas de confusión, desmemoria, depresión e histeria. Es el sitio donde, en la aplicación de los dispositivos disciplinarios y de castigo múltiple, se crean las mismas enfermedades que se pretenden curar.

Matilda no sirve, no puede llevar adelante las consignas de "Orden y progreso", pero tampoco funciona al nuevo proyecto de nación que la revolución, ahora triunfada, quiere configurar, para todos es una prostituta y una loca que no puede "llevar al país hacia delante, hacia el porvenir" (Rivera Garza, 1999, 130).

En "La Castañeda" conoce, o vuelve a encontrar, a Joaquín Buitrago que en el manicomio estrecha amistad con el doctor Eduardo Oligochea, ambos tienen como vínculo común a Matilda. A Oligochea le interesa investigar el porqué Joaquín se interesa de ella, mientras que Buitrago quiere conocer todo de la vida de Matilda y las causas de su enfermedad. Terminará ofreciéndole vivir juntos, después de 28 años transcurridos en el manicomio.

La movilidad de las fronteras internas de los sujetos de la narración se contraponen al insistente trabajo de catalogación que desempeña el Dr. Oligochea. Para él, es fundamental clasificar las diversas enfermedades más que curarlas. Por esto se detiene en cada adjetivo, en cada palabra, pues tiene una suerte de obsesión por el lenguaje:

En su diagnóstico los adjetivos son tan importantes como los términos científicos. Intensa logorrea. Extrañas actitudes prolongadas [...]. Existe algo en los abismos del lenguaje que descubrió Freud que lo seduce y los saca de sus casillas a la vez. Todavía no sabe exactamente por qué, pero las palabras sueltas, desatadas, siempre le han causado vértigo y nunca confianza. Entre las palabras y el olor, él busca uniformidad, exactitud. Un método científico. Lo que él desea es compilar minuciosas observaciones clínicas (Rivera Garza, 1999, 34).

11 Se reproducen en esta cita los caracteres tipográficos utilizados en la novela (Rivera Garza, 1999, 9192) para diferenciar del resto del texto los expedientes de los casos clínicos presentes en el archivo del manicomio. 
De la misma manera, aunque a partir de presupuestos totalmente distintos, también Buitrago con su cámara evidencia la necesidad de fijar, "inmovilizar" lo que se propone retratar. La fotografía es el instrumento con el que pretende fijar las identitades de los internos -ya sea en el próstibulo, ya sea en "La Castañeda"- buscando una suerte de inalterabilidad eterna a la que los distintos sujetos oponen resistencia.

Esta imposibilidad de fijar, así como de normatizar la distintas identidades, es el hilo conductor de la diégesis, puesto que todos los personajes, de una manera u otra, hacen del nomadismo identitario su rasgo peculiar. Lo vemos desde el inicio cuando Matilda encuentra a Diamantina Vicario y Cástulo Rodríguez. Los dos anarquistas presentan características identitarias que desplazan las nociones clásicas de género: Diamantina es una mujer culta, con el hábito de la lectura e inclinada a la música. En su ropero tiene una sola falda de merino, pero suele usar un "overol"12, prenda considerada exclusivamente masculina; tiene "un solo par de zapatos y un sobretodo, ambos negros" (Rivera Garza, 1999, 41). Su casa es el espejo de su esencia, no hay adornos y en la habitación, "además de la mesita de noche y la cama, el lugar estaba vacío. Un cuarto sin muebles: eso era Dimanatina" (41). Esta breve descripción permite focalizar a la revolucionaria en cuanto mujer rebelde que alterna rasgos femeninos con características típicamente masculinas.

Por el contrario, Cástulo Rodríguez -“la rabia de los desamparados” (Rivera Garza, 1999, 113) y símbolo de la resistencia para construir el nuevo futuroes un sujeto que desde siempre ha vivido en los márgenes. En su relación con Matilda va perdiendo las connotaciones masculinas tradicionales que configuran al luchador por la justicia; con una neta inversión de los roles, Rivera Garza confiere a Matilda el papel de mujer segura y determinada, capaz de enfrentar hasta situaciones extremas. Cástulo, en cambio, es visto en su fragilidad interior, que se refleja en un cuerpo "lampiño como el de un recién nacido. No hay vellos en el pecho, brazos o piernas" (Rivera Garza, 1999, 114). Herido por un disparo de la guardia nacional, acude a Matilda para que ella lo cure y le saque la bala. Su "cuerpo indefenso" y la debilidad que muestra a través de su comportamiento lo distancia de la imagen del joven revolucionario temerario, para trasladar a Matilda el papel de la heroína en grado de salvar la situación.

La misma movilidad de roles se encuentra en otras figuras de la novela que expresan su función nómada, al llegar al burdel "La Modernidad" el lector se enfrenta a Madame Porfiria, el dueño de la casa de citas, "un aristócrata venido a menos cuya única debilidad consistía en vestirse de mujer" (Rivera Garza, 1999, 147). Vestía normalmente con un frac negro y pintaba sus labios de un rojo encendido. Rivera Garza hace de Madame Porfiria un personaje totalmente carnavalesco, en el sentido bajtiniano (1987), reforzando de este modo la idea de que normalmente usaba Frida Kahlo, a cuya personalidad, bajo ciertos aspectos, remite Diamantina. 
la hibridación que peculiariza los varios sujetos que transitan en la novela. En el duro trabajo de performance con el que simula el sexo opuesto, Madame Porfiria opera una inversión y una deformación de su rol que da lugar a la parodia y a lo grotesco. Al mismo tiempo el recurso al travestismo sirve como metáfora para representar al régimen de Porfirio Díaz y su proyecto de modernización.

Hombre con semblanzas de mujer, el travesti desmantela las nociones fijas y los cercos rígidos dentro de los cuales se pretende clasificar todo. Es lo que ocurre en el prostíbulo donde ya no hay distinciones, todo está confundido, las identidades de clase, de género y de raza pierden sus contornos netos para dar origen a identidades ambiguas, inestables, que pueden mostrar una cara y esconder otra, exactamente como acontece con el travesti que, al romper la clasificación taxonómica binaria, genera un constante conflicto contra los discursos establecidos.

A su vez Buitrago, en su alienación y aislamiento de la sociedad, muestra cómo se despliega el poder y cómo se resiste a ser dominado. Su rechazo a las conductas adoptadas por su clase, la negación a seguir las huellas paternas en la profesión de médico, la adicción a la morfina y la pasión por la fotografía destacan su forma de resistencia hacia los comportamientos impuestos. Sin embargo, a diferencia de otros personajes, Joaquín escoge su posición, su marginalidad es adquirida de forma consciente, incluso en el ejercicio de su profesión.

En efecto, Buitrago no solo opta por una actividad considerada, de por sí, marginal, sino que la desempeña dentro de los espacios de marginalidad donde deambulan los sujetos excluidos por la modernidad, el progreso o la nueva idea revolucionaria de nación. Su posicionamiento es claro, pero deja vislumbrar su identidad de clase. Puesto que, si bien adopta el margen como espacio de resistencia "a pesar de todo y sin desearlo siquiera, nunca pudo ocultar su porte aristocrático y la apariencia de poseer propiedades y dinero" (Rivera Garza, 1999, 22). Simboliza, entonces, una doble posibilidad, dos posicionamientos, aunque su rechazo al progreso guía sus acciones.

Su obsesión de retratar a los "condenados de la tierra" esconde la pasividad y la inseguridad del personaje, su incapacidad de tomar decisiones definitivas: quiere identificar al otro, mientras trata de ocultarse a sí mismo detrás de la cámara. Al igual que Oligochea, pese a los distintos puntos de partida, Buitrago pretende intepretar, a través de la lente de su cámara, el interior de los sujetos que retrata; su objetivo es llegar a "leer" a Matilda, su vida, sus pensamientos, su real identidad "sin que ésta tenga que tomar parte en este proceso" (Rivera Garza, 1999, 307).

Sin embargo, como ya dicho, así como la cámara debería llegar a lo más íntimo, a la psicología de su modelo, esa misma cámara es el instrumento tras el cual Joaquín se esconde y esconde su fragilidad, sus temores y sus fracasos. Con un salto temporal, la autora vuelve a la infancia de Buitrago y con ella va 
construyendo al personaje mediante unos gestos con los que se propone evidenciar un sujeto que es difícil de encasillar. Sin entrar en mérito a categorías de género, Rivera describe al fotográfo con rasgos peculiares del mundo femenino: "sólo, dándoles las buenas noches con ademanes educados y viendo hacia la oscuridad como si se tratara de una mujer, Joaquín parecía un joven sin objetivos concretos" (Rivera Garza, 1999, 28).

No solo avanzando en la narración se nos retrata a Joaquín en una situación puramente carnavalesca, al presentarse delante de su amigo Oligochea, "ataviado con una túnica de organza que deja entrever sus piernas flacas y el sexo colgando entre las piernas" (Rivera Garza, 1999, 189). El fotógrafo está con la mujer, "dos travestidos inmóviles" (Rivera Garza, 1999, 190) que saben que están siendo diagnosticados por los ojos del poder -en este caso del médico de "La Castañeda"- y por esto deciden evidenciar su consciencia de "observados especiales" a través de la parodización de sus comportamientos.

Ahora es el ojo de Oligochea que lo inmortaliza, Buitrago despierta en él un renovado interés científico, ya que manifiesta una carencia de organización mental, pues es el flujo de consciencia que lo orienta y por esto pierde toda referencia, ya no tiene reglas gramaticales ni números, para él "hablar es desvariar, confunde el tiempo de los verbos y los pronombres. Omite fechas. 'Él', dice, refiriéndose a sí mismo, describiendo a otro" (Rivera Garza, 1999, 30). Se visualiza así la carencia de organización dentro de la mente de Buitrago, descrita como un fluir de la conciencia sin reglas gramaticales ni números a los que ajustarse. En fin, sin puntos fijos, sin normas.

La confusión de tiempos verbales y pronombres está presente no solo en el lenguaje de Buitrago, sino en toda la novela y se contrapone a la obsesión por el lenguaje expresada por Eduardo Oligochea. Más bien, se puede decir que el lenguaje ocupa un lugar de primera plana en la narración, no solo en el cápitulo titulado "Todo es lenguaje", sino a través de múltiples recursos técnicos que lo transforman en uno de los ejes temáticos de la narración.

El lenguaje ayuda a explorar dos mundos distantes entre sí y apunta a destacar la dificultad de expresar la experiencia subjetiva de los distintos personajes una vez que se desmantelan fronteras, cercos y preconceptos. Gracias al uso de una serie de expedientes, el lenguaje logra transgredir su mero propósito comunicativo. La desnaturalización de su función primordial se relaciona con la desnaturalización de la identificación sexual de los distintos sujetos de la novela.

También el cuerpo constituye otro espacio que significa las diferentes categorías genéricas. Cualquiera de ellas -heterosexual, homosexual, bisexual, travesti, etcétera- hace del cuerpo su carta de presentación ante la sociedad, al igual que el poder que, a través del cuerpo, expresa las características represivas cuando este no se corresponde con la norma. El cuerpo, por tanto, se convierte en un narrador de historias inconclusas y deseos a veces ma- 
nifiestos, a veces reprimidos, en cuyo espacio se eviencia la transitividad del sujeto, la presencia de uno en otro. El constante intercambio de roles y parejas sexuales que se observa en el relato hacen que se ilustre abiertamente la descomposición de una sexualidad definida.

Con un recorrido histórico, social, cultural y psicológico en Nadie me verá llorar se quebrantan las fronteras de género, textuales y sexuales, dando lugar a un espacio donde las representaciones del cuerpo y la identidad de los personajes repetidamente cruzan las líneas oficiales de comportamiento, ya sea de género literario -ficción, historia, memoria, testimonio, poesía- ya sea a nivel de las sujetividades que pueblan el relato y que desarman, con distintos modus operandi, las nociones hegemónicas de género.

\section{Conclusiones}

En las producciones discursivas de Mayra Santos-Febres y de Cristina Rivera Garza se traslada al espacio estético la violación de las certezas identitarias a través de la representación de cuerpos permeables que subrayan una estructura abierta a mutaciones y un espacio donde se hacen posibles todos tipos de transgresiones. En ambos casos, los cuerpos disidentes de los distintos personajes narrativos constituyen los espacios de infracción que permiten el traspaso de los límites establecidos en cuanto a identidad y género, dando así lugar a una escritura que "desidentariza" y "degenera" los núcleos internos organizadores de las identidades personales, colectivas y literarias.

Este desmoranamiento de las categorías rígidas se produce por medio del comportamiento de los protagonistas que quiebran los fundamentos de los patrones culturales oficiales para volver a construir, aunque fuertemente obstaculizados, un nuevo territorio identitario a través de estructuras permeables y límites difusos. Y lo hacen mediante sus cuerpos, sus lenguajes y su manera de exteriorizar el deseo y de concebir las relaciones.

En Sirena Selena vestida de pena el/la protagonista emprende un viaje de transformación que cambia, en el sentido más hondo, su yo por medio de artificos y mutaciones. Estos empiezan en el camerino donde se prepara para exhibirse con sus boleros en un escenario que no es más que el punto de encuentro de la simulación que rige la vida del travesti, y que se extienden hasta su psicología y su búsqueda interior. Mediante las reflexiones de su alter ego Leocadio, Sirena se aventura en un camino donde poco a poco va adquiriendo la conciencia de la imposibilidad de establecer una identidad fija y un rol social predeterminado.

La idea del movimiento como rasgo peculiar de toda identidad, entonces, se vuelve central para la interpretación de la novela: movilidad física en el espacio cultural transcaribeño y movilidad sexual y de género con las que se hace posible reconocer nuevas configuraciones identitarias. Al mismo tiempo, se "degeneran" 
también las nociones de género literario mezclando e hibridizando, mediante el bolero, el lenguaje popular con el culto al que pertenece la literatura.

También en Nadie me verá llorar la consciencia de ser cuerpo y de tener cuerpo constituye un elemento central en la configuración identitaria de la protagonista así como de los otros personajes de la novela. Aquí la infracción de los comportamientos normatizados produce segregación y aislamiento del resto de la sociedad. Los distintos sujetos se mueven entre dos espacios rígidamente separados: el espacio del poder y el espacio interior donde se cuestionan los códigos comportamentales reconocidos como idóneos para ser un buen ciudadano. La Historia se contrapone a las historias de los varios sujetos que la atraviesan y que con su manera de actuar ponen en evidencia la necesidad y el deseo de experimentar otros modos de estar en la sociedad, otras maneras de concebir el cuerpo y la sexualidad, la pasión y un nuevo concepto de relación -afectiva y sexual- ya sea heterosexual, homosexual, o bisexual. Rivera Garza desmantela también la idea de género literario entendido como una casilla donde enjaular el texto y abre espacio a una escritura que puede considerarse desidentitaria y "de-generada" en su sentido más completo.

\section{Referencias}

Bajtín, Mijail. (1987). La cultura popular en la Edad Media y en el Renacimiento. El contexto de François Rabelais. Madrid: Alianza.

Butler, Judith. (2000). Imitación e insubordinación de género. Revista de Occidente, (235), 85-109.

Butler, Judith. (2001). El género en Disputa. El feminismo de la subversión y de la indentidad. Barcelona: Paidós.

De Lauretis, Teresa. (2000). Diferencias. Etapa de un camino a través del feminismo. Madrid: Horas y horas.

Foucault, Michel. (1975). Surveiller et punir. Naissance de la prison. Paris: Gallimard.

Foucault, Michel. (1977). Historia de la sexualidad. Madrid: Siglo XXI.

Garber, Marjorie. (1992). Vested Interest. Cross-dressing and Cultural Anxiety. New York: Routledge.

Greimas, Algirdas Julienne. (1990). De la imperfección. México: Fondo de Cultura Económica/Benemérita Universidad Autónoma de Puebla.

Halberstam, Judith. (2008). Masculinidades femeninas. Barcelona-Madrid: Egales.

Kristeva, Julia. (1991). Historias de amor. México: Siglo XXI. 
Kulawik, Krzysztof. (2009). Travestismo lingüístico: el enmascaramiento de la identidad sexual en la narrativa latinoamericana neobarroca. MadridFrankfurt am Main: Iberoamericana.

Merriam Webster Dictionary. Recuperado de http://www.merriam-webster. com/dictionary

Richards, Nelly. (1993). Masculino/Femenino: Prácticas de la diferencia y cultura democrática. Chile: Francisco Zegers Editor.

Ricoeur, Paul. (1986). La metafora viva. Milano: Jaca Book.

Rivera Garza, Cristina. (1999). Nadie me verá llorar. México: Tusquets.

Rubin, Gayle. (1989). Reflexionando sobre el sexo: notas para una teoría radical de la sexualidad. En Vance, Carole. (Ed.). Placer y peligro: explorando la sexualidad femenina. Madrid: Revolución.

Ruffinelli, Jorge. (2008). Ni a tontas ni a locas: notas sobre Cristina Rivera Garza y su nuevo modo de narrar. Nuevo texto crítico, 21(41-42), 33-41.

Santos-Febres, Mayra. (2000). Sirena Selena vestida de pena. Barcelona: Mondadori.

Sarduy, Severo. (1982). Simulación. Caracas: Monte Ávila.

Worldwide Words. (1996-2004). Recuperado de http://www.worldwidewords.org 